\title{
Giant Congenital Melanocytic Nevi and Poliosis in a 3-day-old Boy: Is It Just a Coincidence?
}

\author{
Ahu Yorulmaz ${ }^{1}$, Ayse Akbas ${ }^{1}$ \\ 1 Ankara Bilkent City Hospital, Department of Dermatology, Pediatric Dermatology Unit, Ankara, Turkey \\ Key words: congenital, melanocytic nevi, giant, poliosis, developmental abnormalities \\ Citation: Yorulmaz A, Akbas A. Giant congenital melanocytic nevi and poliosis in a 3-day-old boy: is it just a coincidence? \\ Dermatol Pract Concept. 2022;12(1):e2022040. DOI: https://doi.org/10.5826/dpc.1201a40 \\ Accepted: July 10, 2021; Published: January 2022 \\ Copyright: (C2022 Yorulmaz and Akbas. This is an open-access article distributed under the terms of the Creative Commons \\ Attribution License BY-NC-4.0, https://creativecommons.org/licenses/by-nc/4.0/, which permits unrestricted noncommercial use, \\ distribution, and reproduction in any medium, provided the original authors and source are credited. \\ Funding: None. \\ Competing interests: None. \\ Authorship: All authors have contributed significantly to this publication. \\ Corresponding author: Ahu Yorulmaz, Ankara Bilkent City Hospital, Department of Dermatology, Universiteler Ankara. \\ E-mail: ahuyor@gmail.com
}

\section{Introduction}

Giant congenital melanocytic nevi (GCMN) are rare benign nevomelanocytic proliferations that are expected to reach a diameter of at least $20 \mathrm{~cm}$ in adulthood. Here, we present a case of GCMN associated with poliosis.

\section{Case Presentation}

A 3-day-old baby boy, born of a non-consanguineous marriage, was examined at our pediatric dermatology outpatient clinic for a black nevus on his back. He was otherwise healthy and his family history was unremarkable. We observed a black patch measuring approximately $10 \mathrm{~cm} \times 15 \mathrm{~cm}$ in size on the left upper back of the patient. A localized patch of white hair on the occiput and satellite nevi on the face, trunk and extremities of the patient were also noticed (Figure 1). A thorough neurological examination and magnetic resonance imaging of the brain and spine didn't reveal any pathology. Diagnoses of GCMN and poliosis were made and the patient was taken under follow-up.

\section{Conclusions}

This is the third report in the literature describing the coexistence of GCMN and poliosis [1,2]. In 1999 Yosipovitch et al presented a patient with GCMN with poliosis [1] and in 2013 Lee et al reported a patient with GCMN of the scalp with cranial defect, poliosis and hair loss [2]. GCMN have been associated with several developmental abnormalities, including cutis verticis gyrata, limb atrophy/hypertrophy and hamartomas. Postzygotic mutations affecting somatic cells may provide one explanation of the occurrence of these associations. Mutations in NRAS, BRAF, and Tp53 have been specified in congenital melanocytic nevi (CMN) samples. If the mutation develops early enough, it can affect a multipotent progenitor cell, leading not only to $\mathrm{CMN}$ in the cutaneous tissue, but also abnormalities in the other organs. Given the accompanying cranial defect and alopecia, Lee et al proposed that the destruction of cranium, hair follicles and bulb melanocytes might have been caused by an inflammatory or autoimmune response, or even the destructive potential of the nevus cells per se [2]. 


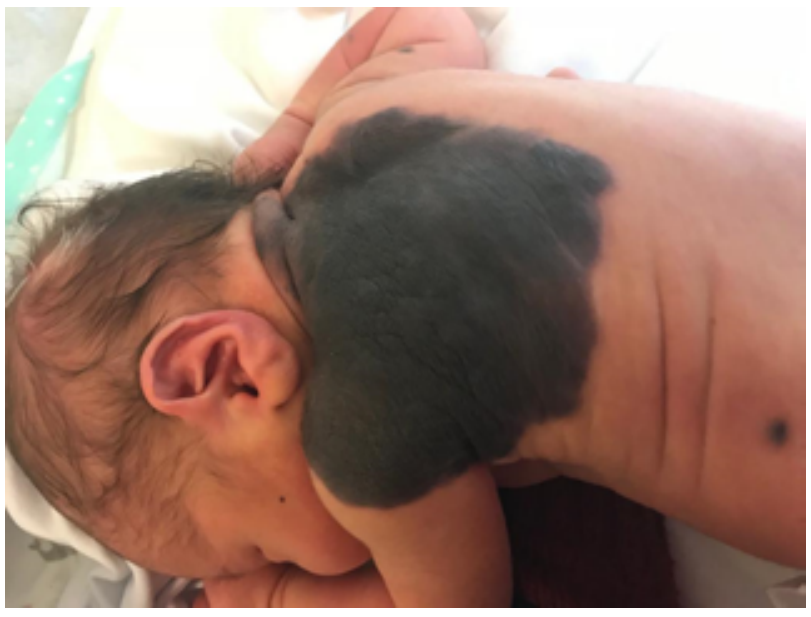

Figure 1. A bolero type giant congenital melanocytic nevi measuring approximately $10 \mathrm{~cm} \times 15 \mathrm{~cm}$ in size on the left upper back of the patient. Note the poliosis on the occiput.

Poliosis, which is defined as a localized patch of white hair within a group of hair follicles, has been described in association with different genetic or acquired conditions, including benign and malignant melanocytic neoplasms. A perifollicular lymphohistiocytic infiltration suggests an inflammatory/ autoimmune response as the causative mechanism in the pathogenesis of poliosis in patients with melanocytic lesions. Another suggested theory involves the migration arrest of fetal melanocytes into the hair bulbs. It is well-known that melanoblasts originate from pluripotent precursor neural crest cells, migrate along defined pathways and differentiate into melanocytes.

The fact that poliosis may arise embryogenetically strongly implies the role of genes in the pathogenesis of poliosis associated with GCMN. However, the main question still remains unclear: is poliosis an associated feature of melanocytic lesions or is the coexistence of poliosis and GCMN in the same individual a coincidental finding? If this is a real association, what's the exact underlying mechanism in the pathogenesis? Further case reports will allow the pathogenesis of the association between GCMN and poliosis to be better understood.

Informed consent: Written informed consent for publication of clinical details and clinical images was obtained from the patient's parents.

\section{References}

1. Yosipovitch G, Feinmesser M, Mutalik S. Poliosis associated with a giant congenital nevus. Arch Dermatol. 1999;135(7):859-861. DOI: 10.1001/archderm.135.7.859. PMID: 10411174.

2. Lee $\mathrm{WJ}$, Lee $\mathrm{SM}$, Won $\mathrm{CH}$, et al. Coexistence of congenital giant melanocytic nevus of the scalp with cranial defect, poliosis, and hair loss. Pediatr Dermatol. 2013;30(6):e226-e227. DOI: 10.1111/pde.12101. PMID: 23437823. 